\title{
Principios y fundamentos del Derecho público del deporte
}

GABriel REAL FERRER

El deporte constituye, sin duda uno de los fenómenos sociales y económicos más importantes de los aparecidos en este siglo. Tanto en su vertiente de práctica personal, ocasional o cotidiana, como en su aspecto de espectáculo de masas, el deporte suscita el interés creciente de los ciudadanos y en su entorno se genera un complejo entramado de relaciones jurídicas de singulares características no suficientemente estudiadas.

Por su parte, los poderes públicos destinan recursos cada vez mayores al atendimiento de las demandas colectivas en este campo, lo que se traduce en la emergencia de un buen número de órganos de la llamada Administración deportiva en los niveles estatal, autonómico y local.

Por si ello fuera poco como para despertar el interés de los juristas, el deporte se organiza como un cuerpo social homogéneo dotado de su propia normación, configurándose como un afinado ejemplo de un ordenamiento jurídico espontáneo y con pretensión de autonomía. No obstante, el campo de las actividades deportivas y las estrechas relaciones existentes entre dos universos aparentemente tan dispares como son el Derecho y el Deporte, vienen siendo cuestiones que, a salvo de notables excepciones, son sistemáticamente desasistidos por la doctrina científi$\mathrm{ca}$, atenazada, por un cúmulo de prejuicios que tienden a considerar como una "cuestión menor» este campo del actuar humano.

Este relativo abandono tiene su reflejo en la aparatosa ausencia de criterios seguros con los que abordar muchos de los singulares conflictos que plantea el derecho deportivo, ante los cuales, se estremece la 
ortodoxia. Incluso la propia consideración del acceso a su práctica como uno de los nuevos derechos fundamentales de carácter social, se manifiesta como una cuestión escasamente debatida frente a la que las legislaciones nacionales se muestran titubeantes.

En este contexto se sitúa este trabajo que tiene como objetivo el colaborar en la construcción de un corpus teórico que permita abordar esta faceta de lo jurídico con un suficiente bagaje conceptual. En este sentido, el punto de mira se centra en las responsabilidades que, al respecto, atañen a los poderes públicos y en intentar alumbrar los principios que inspiran a la que es su herramienta de intervención en la materia: El Derecho Público del Deporte.

Desde el punto de vista sistemático, el trabajo se estructura en cuatro capítulos. El primero se destina a fijar conceptualmente lo que, de suyo, constituyen las premisas para abordar el análisis de la cuestión, a saber, ¿qué debemos entender por deporte?, ¿cómo se estructura socialmente?, ¿qué caracteres distinguen al ordenamiento jurídico que le resulta propio?, y, por último, ¿cómo se articulan las relaciones entre esos dos complejos normativos que son el deporte y el derecho del Estado? También se adelanta una definición, en este primer capítulo, de lo que entendemos por Derecho Público del Deporte: aquel conjunto normativo constituido por las disposiciones emanadas de los distintos poderes públicos, mediante las que se imponen u orientan las conductas de los agentes deportivos en un sentido comunitariamente relevante.

El capítulo segundo se destina al análisis comparado de distintos sistemas jurídico-deportivos nacionales que, por una u otra razón, resultan relevantes en el contexto económico-social en el que se incardina nuestro modelo de intervención. Los sistemas examinados son: Francia, Gran Bretaña, Alemania, Italia, Estados Unidos, Canadá y Australia.

En el tercero de los capítulos se establecen los antecedentes de nuestro actual modelo deportivo rastreando las actuaciones públicas realizadas en nuestro país y deteniéndose, singularmente, en el modelo rigurosamente intervencionista que periclita con la Constitución del 1978. Se analiza aquí, también, la «transición deportiva» que, plagada de dificultades, debe concluir con la aprobación de la Ley del Deporte de 1990. 
El cuarto y último capítulo tiene por objeto la descripción de los rasgos más característicos de nuestro actual Derecho Público del Deporte desde la óptica constitucional, destinándose buena parte del mismo al estudio de la naturaleza e intensidad de las obligaciones públicas en el sector y a adelantar criterios en torno a los complejos mecanismos de atribución de competencias entre las distintas instancias públicas. Finalmente se justifica el título del trabajo tratando de explicitar alguno de los principios inspiradores de este particular cuerpo normativo. 